\title{
Dynamic behaviour of an undulating membrane tidal energy converter under wave and current loading
}

\author{
Träsch Martin 1, ${ }^{*}$, Delacroix Sylvain ${ }^{1}$, Déporte Astrid ${ }^{1}$, Drevet Jean-Baptiste ${ }^{1}$, Gaurier Benoit 2 , \\ Germain Gregory ${ }^{2}$
}

1 EEL ENERGY, 60, rue de Folkestone 62200 Boulogne sur Mer, France

2 IFREMER, Marine Structure Laboratory, 150 Quai Gambetta 62200 Boulogne sur Mer, France

* Corresponding author : Martin Träsch, email address : $\underline{\text { mtrasch@eel-energy.fr }}$

\begin{abstract}
:
The dynamic behaviour of an undulating tidal energy converter under wave and current loadings is studied. Therefore, a small scale prototype of a damped pre-stressed undulating membrane is tested in a wave and current recirculatory tank. The membrane's dynamic profile and hydrodynamic forces are measured synchronously with the surface elevation for both regular and irregular waves in current direction. Spectrum analysis reveals that the response to wave loading depends on the wave frequency and is reduced by damping-type power take-off. Coupling between the wave frequency and the main undulation frequency or its harmonics is also observed. An increase of $30 \%$ of the forces must be foreseen in case of wave condition in the tested range.
\end{abstract}

\section{Highlights}

- Undulating membrane tidal energy converter's response under wave and current. Waves increase hydrodynamic loading fluctuations on the membrane. Power Take-Off reduces the influence of wave loading on the membrane. Synchronization occurs when wave frequency is close to the system's fundamental.

Keywords : Fluid-structure interaction, Renewable energy, Tidal energy, Undulating membrane, Flume tank, Wave-current interaction 


\section{Introduction}

Understanding the impact that the extreme marine environment has on the survivability of tidal energy converters is fundamental for the successful development and commercialisation of full scale devices. Recent efforts from the scientific community to drive the development of tidal technology forward include the estimation of turbulence [1] [2] or wave loading [3], [4], [5], [6] effects, on tidal energy devices. These investigations cover a wide range of topics ranging from the influences of diverse waveforms, wave directionality, control strategies or turbulent flow characteristics and intensities. 
These studies proved that waves can significantly impact the behavior of classical horizontal axis tidal turbine [7]. Cyclic loading increases drag and power variations. It also contributes to blade fatigue and extreme loading, affecting tidal converters lifespan [8], [6], [9]. While most of these studies consider rigid structures, recent developments suggest that flexibility can reduce the wave induced loading on turbine blades [10]. If the first conclusions on how the waves can affect classical tidal energy converters behavior have been addressed, specific studies are needed for non generic systems such as pre-stressed undulating membrane tidal energy converter.

The device studied here aims to use membrane deformation to activate electromagnetic converters. Therefore, it uses a strain wave generated by interactions between a pre-stressed semi-rigid structure and an axial flow. The membrane characteristics are chosen to be rigid enough to transmit the deformation force to converters and flexible enough to be deformed by the flow. Indeed, above a critical flow speed, differential of pressure increases and curves the membrane. The position becomes unstable and the strain wave is propagated from the leading edge to the trailing edge.

The undulating membrane tidal energy converter has been studied in a flume tank [11], but until now it has never been submitted to both waves and current. Yet the undulating behavior of undulating membrane tidal energy converter is a hint that complex interactions can happen depending on the waves frequency and/or their wavelength. Sea trials have also revealed a certain sensitivity to swell, however the instrumentation was not suited to correctly analyse this phenomenon [12]. The knowledge of the interactions between surface waves and the undulating membrane, as well as of the effects of waves loading on the structure is an essential requirement to design a system that can undergo long-term sea trials. Therefore, the effects of surface waves on the behavior of an undulating membrane tidal energy converter are studied in this paper. Combined trials with current and waves in the same direction have been set up in the IFREMER flume tank of Boulogne-sur-Mer. The results of these tests are presented in the following, considering regular waves of several heights and periods, as well as irregular waves following a JONSWAP spectrum [13].

The experimental set-up is first described. Then, the influence of regular surface waves on the flow speed profile is presented and the membrane's dynamic profile is studied. In the end, the hydrodynamic loads are assessed for both regular and irregular waves. 


\section{Experimental set-up}

\subsection{Prototype and instrumentation}

Trials have been carried out in the IFREMER wave and current recirculatory tank of Boulogne sur Mer (Fig. 1), with an upstream flow speed of $U_{\infty}=1 \mathrm{~m} / \mathrm{s}$. The tank section is 4 meters wide and $h=2$ meters high.

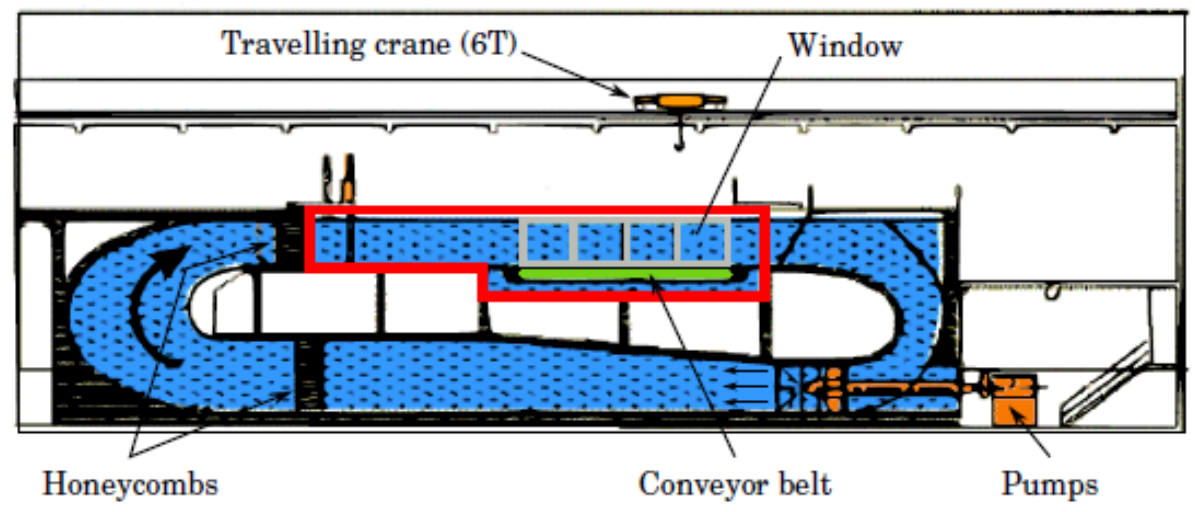

Figure 1: Drawing of Ifremer's waves and fume tank of Boulogne-sur-Mer

The wave generator is composed of 8 independent displacement paddles. It can be placed upstream or downstream and can generates waves with a frequency from $f_{\text {wave }}=0.5 \mathrm{~Hz}$ to $f_{\text {wave }}=2 \mathrm{~Hz}$, with a maximum amplitude of $A_{\text {wave }}=0.280 \mathrm{~m}$ for the tested current speed. In these conditions, the reflection coefficient is less than $12 \%$ [7].

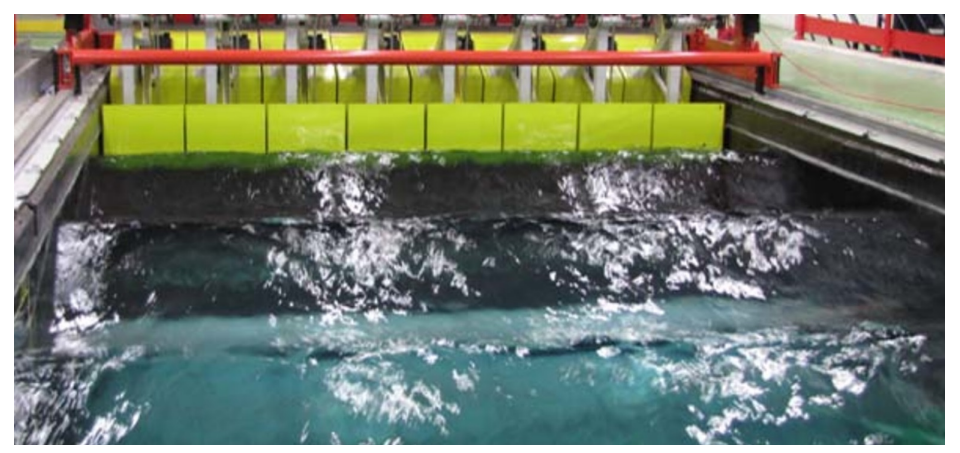

Figure 2: Picture of the wave generator performing regular waves 
The axial, transverse and vertical components of the flow speed are noted $u, v$ and $w$, respectively in the $x, y$ and $z$ directions (Fig. 3). Turbulence intensity characterizes the level of fluctuations in the flow as a percentage of the average velocity. It is calculated here on two components (Eq. 1), with $(\cdot)$ the mean value and $\sigma$ the standard deviation.

$$
I_{2 D}=100 \sqrt{\frac{1}{2} \frac{\sigma(u)^{2}+\sigma(w)^{2}}{\bar{u}^{2}+\bar{w}^{2}}}
$$

The prototype used in these trials is a polyacetal membrane of length $L$ $=0.8 \mathrm{~m}$, width $b=0.8 \mathrm{~m}$ and thickness $e=0.003 \mathrm{~m}$ (Fig. 4). It is clamped to a stainless steel frame through three polyacetal bars of dimensions $0.25 \mathrm{~m}$ $\times 0.05 \mathrm{~m} \times 0.01 \mathrm{~m}$.

The membrane is buckled by two pre-stress cables on the side that link its downstream end to the fixation frame. The sideways cables are shorter than the distance between their fixation points when the membrane is flat.They maintain the membrane bended, which reduces the minimum flow speed at which the system becomes unstable and starts to undulate, called the critical flow speed $U_{c}$. The pre-stress cables length is also a control parameter over the undulations amplitude and the membrane behaviour. It is characterized by the pre-stress cables withdraw length ratio $d$, calculated by Eq. 2 .

$$
d=\frac{L+L_{\text {fixations }}-L_{\text {cables }}}{L}
$$

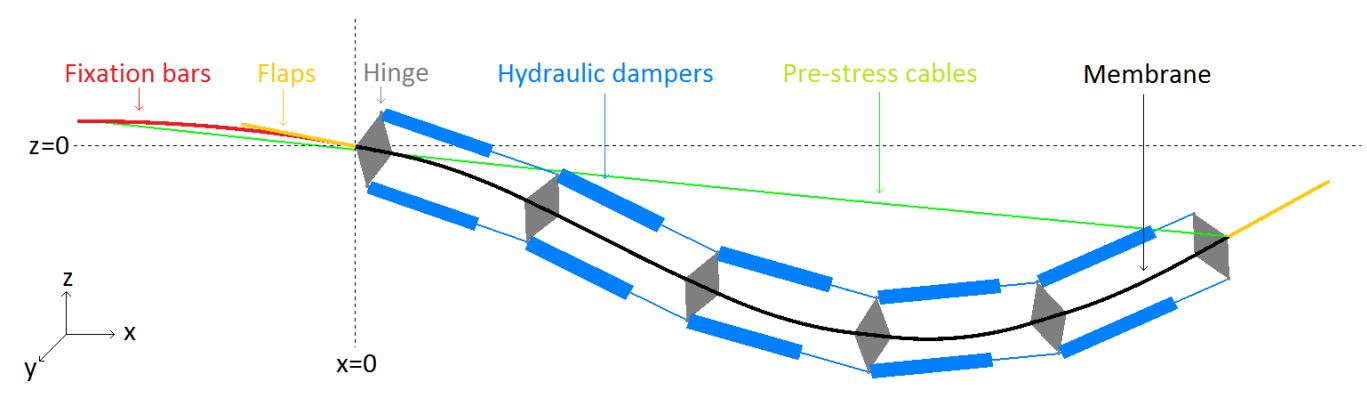

Figure 3: Two-dimensional scheme of the prototype 
Adjustable hydraulic dampers are used to model linear electric converter. They are fixed on the membrane by $35 \mathrm{~mm}$-height hinges (Fig. 3). Their average damping coefficient is about $C=3000 \mathrm{~kg} / \mathrm{s}$ [11]. Six $0.025 \mathrm{~L}$-wide carbon-epoxy rectangular prism are put in the transverse direction in order to increase the transverse stiffness and to ensure a two-dimensional motion, they are separated by $0.2 \mathrm{~L}$ on the membrane and transmit forces to the converters through hinges. This membrane is also lengthened by $0.15 \mathrm{~L}$-long rigid flaps at both upstream and downstream extremities.

The prototype's kinetics is measured by a 2-D motion-tracking system composed of six targets along the membrane and a Qualysis Oqus 310 camera $(1024 \mathrm{px} \times 1296 \mathrm{px})$. Forces on the structure are obtained by a sixcomponents load cell (Fig. 5). Membrane's drag $F_{x}$ and lift $F_{z}$ are calculated by removing the frame-induced forces from the load cell measurements. Sampling frequency is $f_{s}=100 \mathrm{~Hz}$ and a trial lasts $300 \mathrm{~s}(\approx 60$ undulating periods). Stream velocity $(u, v)$ is measured in the $(x, y)$ directions with a $2 \mathrm{D}$ Laser Doppler Velocimetry (LDV) system placed upstream of the structure, at $(x, y, z)=(-2 \mathrm{~m}, 0 \mathrm{~m}, 0 \mathrm{~m})[14]$. Free surface elevation is measured by the mean of a wave gauge system with three wave probes situated at $1000 \mathrm{~mm}$ on the side and respectively at $0 \mathrm{~mm}, 800 \mathrm{~mm}$ and $1200 \mathrm{~mm}$ upstream from the undulating tidal converter. All the measurement systems are synchronized.

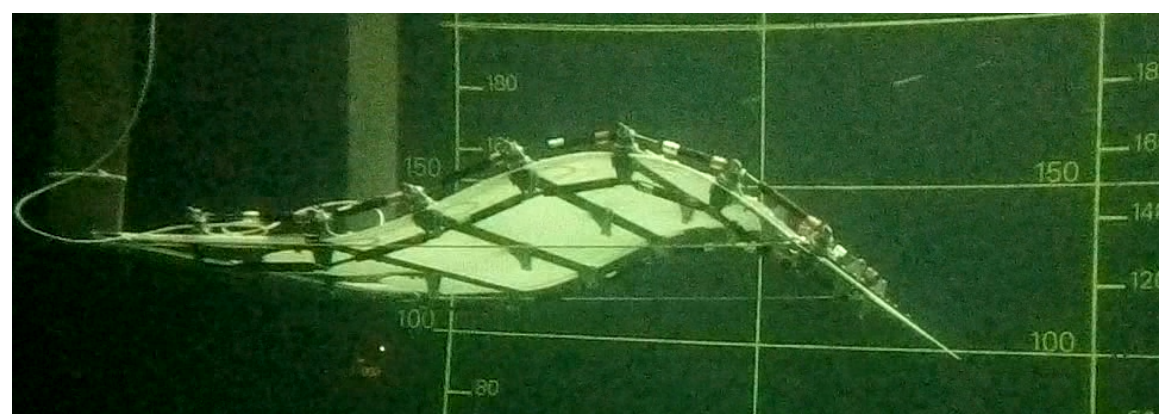

Figure 4: Picture of the prototype during trials with two lines of dampers

Tested configurations are summarized in Table 1. Two parameters are modified between the configurations : the dampers number (implying additional damping and mass) and the withdraw length of pre-stress cables. Tested wave range from $f_{\text {wave }}=0.5 \mathrm{~Hz}$ to $0.8 \mathrm{~Hz}$ and up to $A_{\text {wave }}=0.3 \mathrm{~m}$. 


\begin{tabular}{crrr}
\hline Config. & Mass & Damping & Withdraw length \\
\hline$C_{1}$ & $8.60 \mathrm{~kg}$ & 0 & $5 \%$ \\
$C_{2}$ & $9.35 \mathrm{~kg}$ & $12 \times 3000 \mathrm{~kg} / \mathrm{s}$ & $5 \%$ \\
$C_{3}$ & $10.1 \mathrm{~kg}$ & $24 \times 3000 \mathrm{~kg} / \mathrm{s}$ & $5 \%$ \\
$C_{4}$ & $10.1 \mathrm{~kg}$ & $24 \times 3000 \mathrm{~kg} / \mathrm{s}$ & $10 \%$ \\
\hline
\end{tabular}

Table 1: Summary of tested configurations

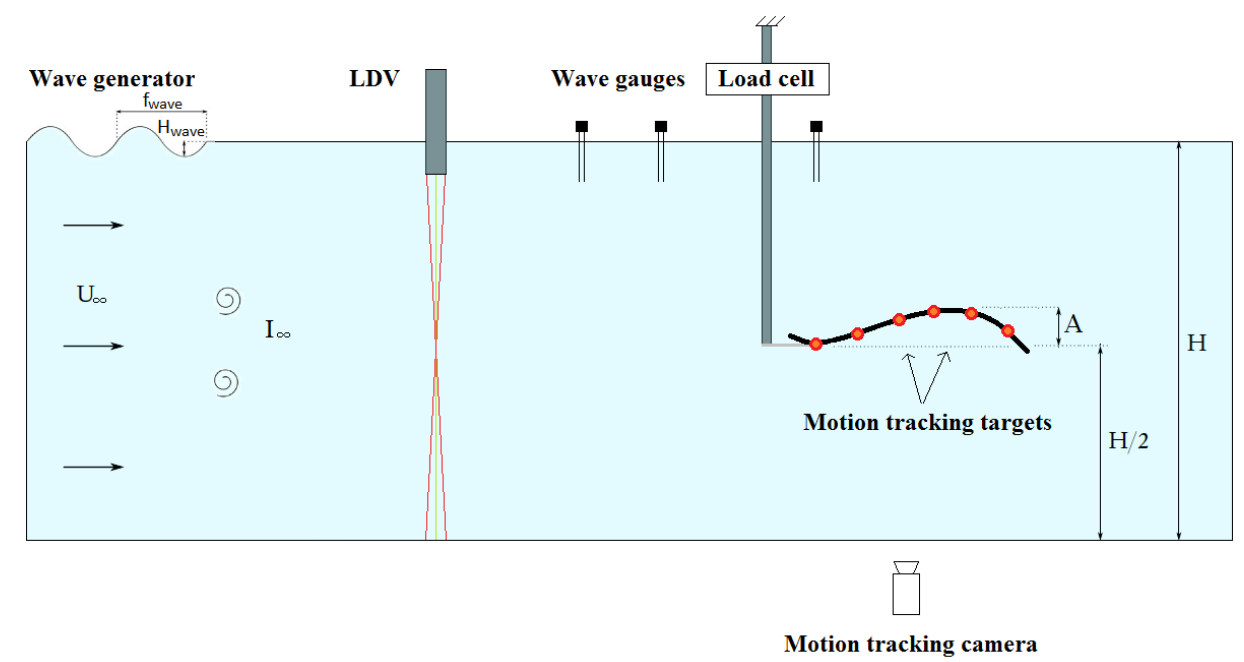

Figure 5: Drawing of the experimental set-up including instrumentation locations around the prototype

\subsection{Flow characteristics}

The wave generator is placed upstream. It is an obstacle in the flow, whether it is static or moving. It modifies the stream profile and its turbulence intensity. In these experiments, LDV measurements for $(u, v)$ components are made in a single point during trials with the prototype, but the current profile with $(u, w)$ components has been characterized without the prototype. The velocity profile without any obstacle is uniform along the test area at $1 \mathrm{~m} / \mathrm{s}$ with $1.5 \%$ turbulent intensity [7]. Velocity profiles with static and moving wave generator are represented in Figs. $6 \&$ 8 . A notable feature is the velocity deficit in the flume tank upper part. However, the current profile is less impacted at the membrane's undulation levels, with $\bar{u} \in[0.95,1.08] \mathrm{m} / \mathrm{s}$ and $\bar{w} \in[-0.013,0.010] \mathrm{m} / \mathrm{s}$ for $z \in[-0.3,0.3] \mathrm{m}$. 

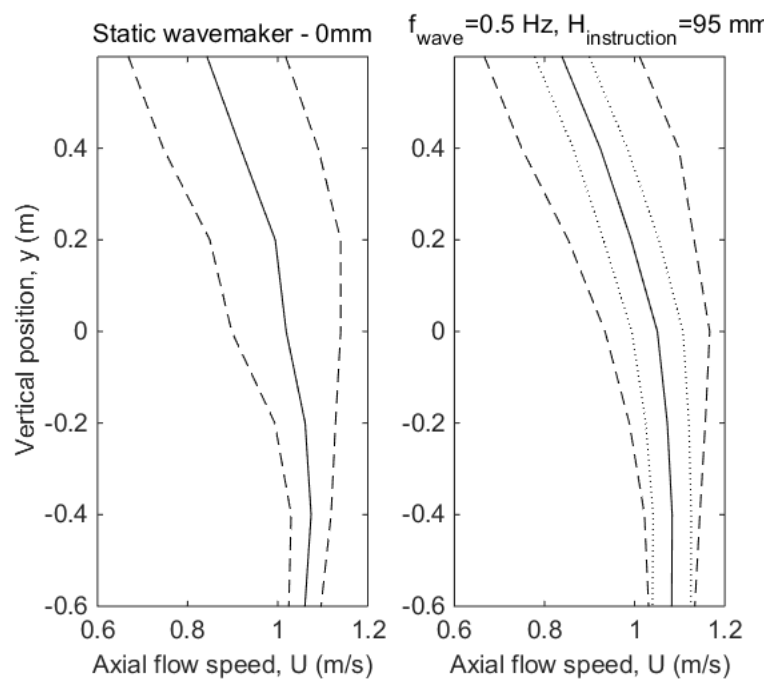

Figure 6: Axial velocity profile with static (left) and moving (right) wavegenerator. Full line : mean value $(\bar{u})$, dashed line : standard deviation $(\bar{u} \pm \sigma(u))$, dotted line : wave orbital speed $\left(u_{\text {orbital }}\right)$.
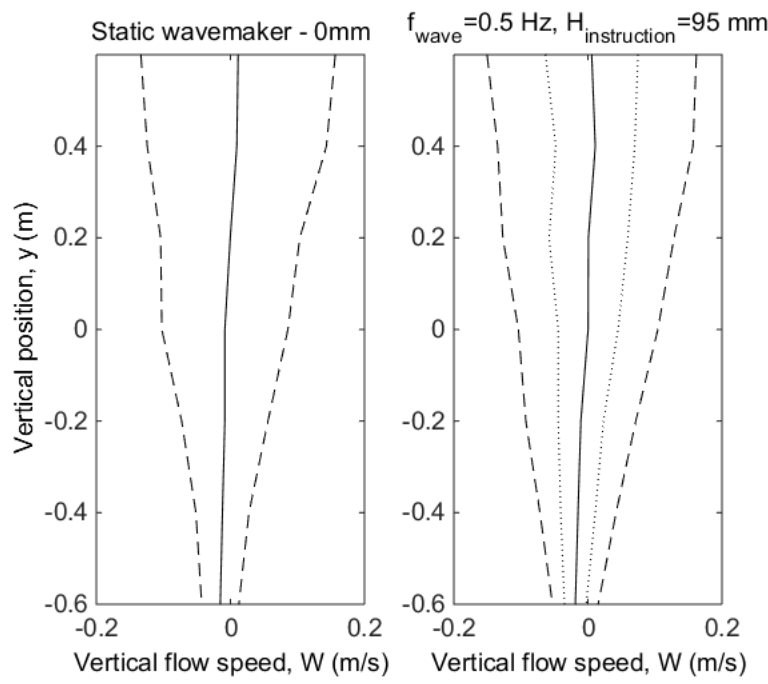

Figure 7: Vertical velocity profile with static (left) and moving (right) wavegenerator. Full line : mean value $(\bar{w})$, dashed line : standard deviation $(\bar{w} \pm \sigma(w))$, dotted line : wave orbital speed ( $\left.w_{\text {orbital }}\right)$. 
Fig. 8 presents an example of water surface elevation measured by the wave gauge placed at $x=0$ during one trial. It shows a high variability of wave heights, even for a fixed regular wave instruction. Here, $f_{\text {wave }}=0.6$ $\mathrm{Hz}$ and the mean peak-to-crest wave height is $\bar{H}_{\text {wave }}=0.108 \mathrm{~m}$, with 0.015 m standard deviation. Significant wave height is $H_{s}=0.13 \mathrm{~m}$, calculated as being 4 times the standard deviation of the free surface elevation (Eq. 3). Wave heights variations come from the interactions between the current and the wave generator. The wave frequency is however stable and match the expected value. In the following, it will be more efficient to analyse results in terms of frequency than regarding the wave amplitude.

$$
H_{s}=4 \sigma\left(z_{\text {surface }}\right)
$$

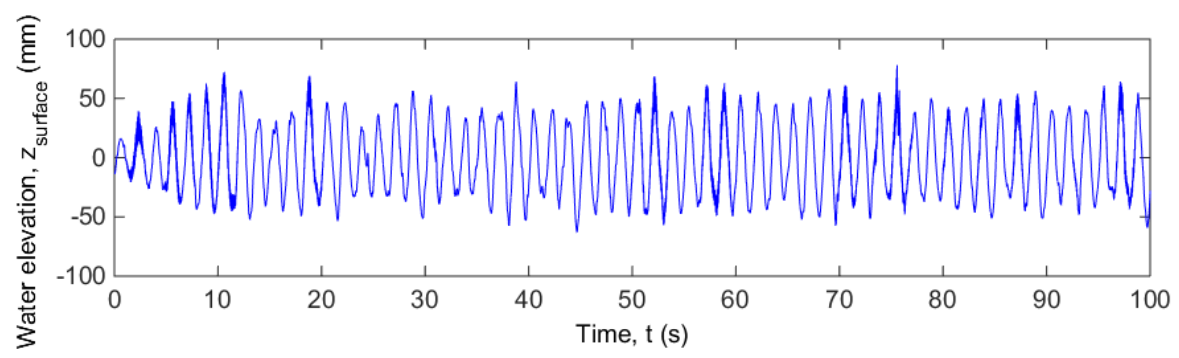

Figure 8: Wave gauge measurement results example in $(x, y)=(0,1.25 L)$, at $U_{\infty}=1 \mathrm{~m} / \mathrm{s}$, $f_{\text {wave }}=0.6 \mathrm{~Hz}$ and $H_{s}=0.13 \mathrm{~m} . t=0$ is the time of the first generated wave passing by.

The response of current velocity fluctuations to waves is presented in Fig. 9 , where the power spectral density of the flow is plotted for a representative trial with regular waves. This spectrum has been calculated from data irregularly sampled as it comes from LDV measurement. It has been obtained after a linear interpolation at a sampling frequency equal to the biggest interval between two measurements $(<0.01 \mathrm{~s})$. The signal has then been filtered by a method described in [2]. As expected, the axial flow speed spectrum has a peak at the wave frequency. The transverse flow speed spectrum, on the opposite, does not seem impacted by the waves. Both spectrum have a slope close to $-5 / 3$ in the inertial range. The flow speed spectrum without wave can be superimposed to Fig. 9 , except in $f=f_{\text {wave }}$, where it does not present any peak. The spectrum without wave generator has lower levels of power density and also has a $-5 / 3$ slope in the inertial range [1]. 


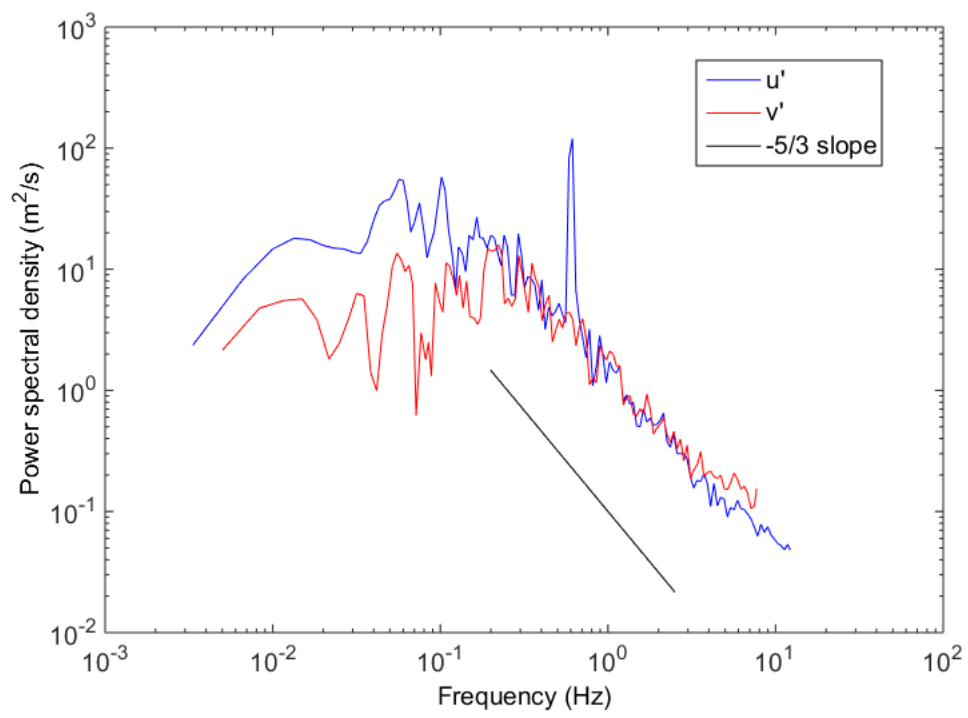

Figure 9: Power spectral density of fluctuating flow speed in $(x, y, z)=(-2.4 L, 0,0)$, for $U_{\infty}=1 \mathrm{~m} / \mathrm{s}, f_{\text {wave }}=0.6 \mathrm{~Hz}, H_{s}=0.13 \mathrm{~m}$.

The wave orbital speed is estimated at the LDV measurement point $(x, y, z)=(-2.4 L, 0,0)$ by a Fast Fourier Transform (FFT) bandpass filter eliminating the frequencies further than $\pm 10 \%$ from the wave frequency. It is estimated to be $u_{o r b}^{\max }=0.06 \pm 0.06 \mathrm{~m} / \mathrm{s}$, for the following wave and current conditions : $\left[U_{\infty}=1 \mathrm{~m} / \mathrm{s}, f_{\text {wave }}=0.6 \mathrm{~Hz}, H_{s}=0.13 \mathrm{~m}\right]$.

The wavelength is obtained by calculating the wave celerity through crosscorrelation between the wave gauges signals. The celerity is then the axial distance between two wave gauges divided by the duration corresponding to the maximum correlation between both signals. This calculus gives $\lambda=6.45$ $\mathrm{m}$ for the above-mentioned wave and current conditions.

This is consistent with the wavelength calculated by iterating the dispersion relation with Doppler shift (Eq. 4), which gives $\lambda=7.04 \mathrm{~m} \mathrm{[16].} \mathrm{The}$ intermediate depth hypothesis is then confirmed. Moreover, the wavelength is several times greater than the membrane's length, which is representative of real sea state conditions.

$$
2 \pi f_{\text {wave }}-\frac{2 \pi U}{\lambda}=\sqrt{\frac{2 \pi g}{\lambda} \tanh \left(\frac{2 \pi h}{\lambda}\right)}
$$


Real scale values give a better idea of the tested wave range. Therefore, respecting geometric and dynamic scaling for the structure [12] and Froude scaling for the fluid (Eq. 5, $F_{r}=0.36$ ), tested waves with significant height $H_{s}=0.28 \mathrm{~m}$ and frequency $f_{\text {wave }}=0.8 \mathrm{~Hz}$ are representative of real scale waves of significant height $H_{s}=5.1 \mathrm{~m}$, frequency $f_{\text {wave }}=0.19 \mathrm{~Hz}$ and wavelength $\lambda=43 \mathrm{~m}$ (Eq. 4) on a 15m-long undulating membrane tidal energy converter.

$$
F_{r}=\frac{U_{\infty}}{\sqrt{g L}}
$$

\section{Membrane dynamic behaviour}

\subsection{Membrane undulating motion}

Flow perturbations from the wave generator presence and their effects on the undulating membrane tidal energy converter are resumed in Table 2 and in Figs. 10. It increases mean upstream axial flow speed by $5 \%$ at LDV measurement point, resulting in a 10\% difference in the membrane undulation frequency. It also increases upstream turbulence intensity, generating little disturbance that modifies the motion frequency spectrum. These flow disturbances increase the maximum amplitude of vertical motion and lift force. The presence of the wavemaker has then a significant impact on the device undulations, therefore it must be documented to distinguish its effects from the waves'.

\begin{tabular}{|l|c|r|r|}
\hline Parameter & Symbol & With generator & Without \\
\hline Mean axial flow speed & $\bar{U}$ & $1.065 \mathrm{~m} / \mathrm{s}$ & $1.009 \mathrm{~m} / \mathrm{s}$ \\
Mean transverse flow speed & $\bar{V}$ & $0.010 \mathrm{~m} / \mathrm{s}$ & $0.007 \mathrm{~m} / \mathrm{s}$ \\
Turbulent intensity & $I_{\infty}$ & $8.22 \%$ & $1.46 \%$ \\
\hline Undulation frequency & $f$ & $0.256 \mathrm{~Hz}$ & $0.231 \mathrm{~Hz}$ \\
Motion amplitude & $A$ & $0.578 \mathrm{~m}$ & $0.486 \mathrm{~m}$ \\
Maximum drag force & $F_{d}$ & $127 \mathrm{~N}$ & $120 \mathrm{~N}$ \\
Maximum lift force & $F_{l}$ & $239 \mathrm{~N}$ & $170 \mathrm{~N}$ \\
\hline
\end{tabular}

Table 2: Influence of the wave generator on flow characteristics and membrane behaviour, without wave generation. $U_{\infty}=1 \mathrm{~m} / \mathrm{s}, d=5 \%, C=24 \times 3000 \mathrm{~kg} / \mathrm{s}$ 

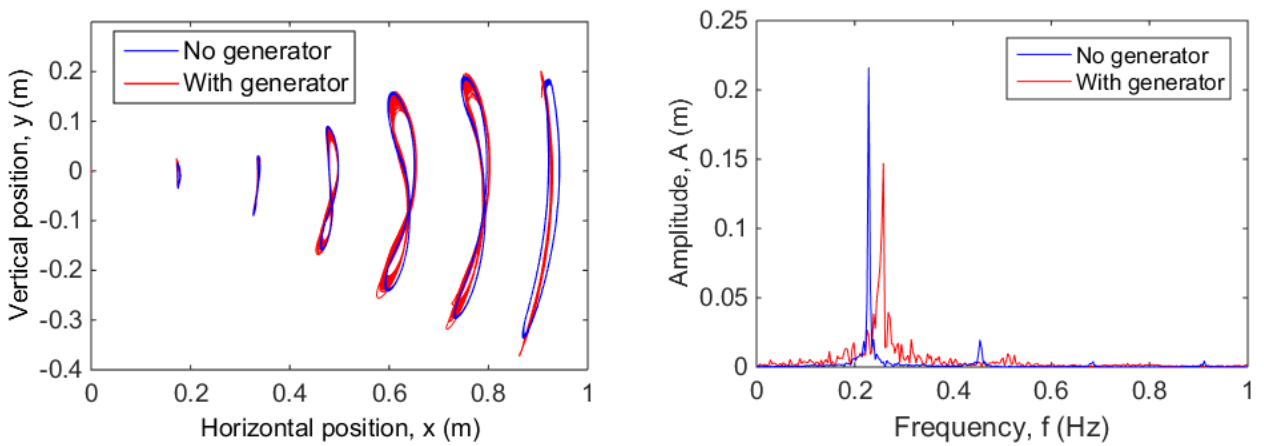

Figure 10: Influence of the motionless wave generator on the position of the membrane's motion-tracking targets (left) and the membrane downstream end vertical motion frequency spectrum (right). $U_{\infty}=1 \mathrm{~m} / \mathrm{s}, d=5 \%, C=24 \times 3000 \mathrm{~kg} / \mathrm{s}$

Fig. 11 presents the vertical displacement of motion-tracking targets along the membrane during two trials : one with the wave generator immersed in the tank but static and another for which it generates waves at $f_{\text {wave }}=0.6 \mathrm{~Hz}$ and $H_{s}=0.13 \mathrm{~m}$. It shows that there is indeed an effect of the waves on the membrane's motion. The membrane kinetics being fully periodic in the configuration without wave and presenting amplitude variations from an undulation period to another in the configuration with regular waves.

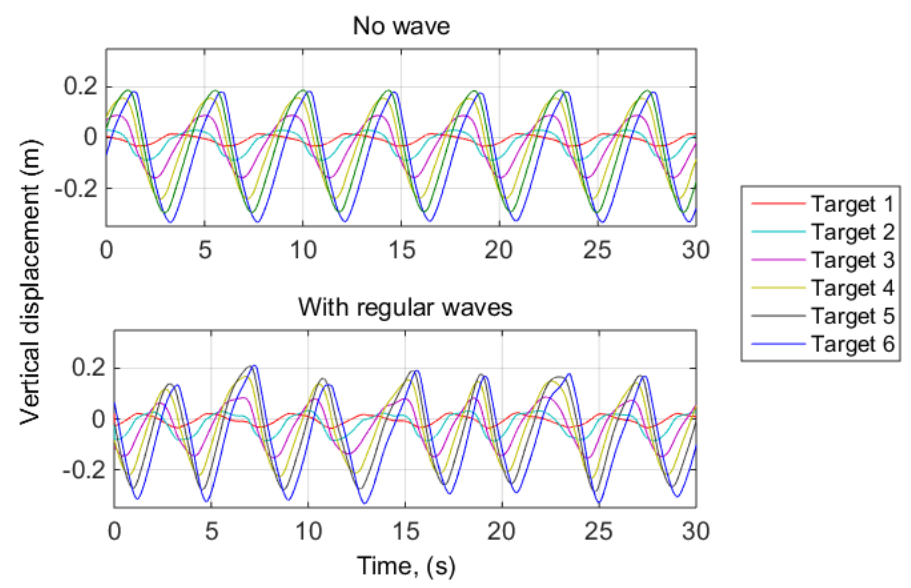

Figure 11: Vertical position of control points on the membrane, separated by $0.2 L$, during 10 undulation periods without wave (top) and with wave (bottom). $U_{\infty}=1 \mathrm{~m} / \mathrm{s}, d=5$ $\%, C=24 \times 3000 \mathrm{~kg} / \mathrm{s}$ 
In the following results, undulation and wave frequencies, as well as their harmonics, are non-dimensionalized by the membrane length and the upstream mean current speed according to Eq. 6. It is then equivalent to the inverse Stokes number and is used to extrapolate results more easily to different scales.

$$
f^{*}=\frac{f L}{U_{\infty}}
$$

Fig. 12 presents the effects of generated wave frequency and wave height on the trailing edge mean motion amplitude for each tested configuration. Indeed, amplitude at trailing edge is representative of the undulation amplitude along the membrane's length, as the undulation mode does not change due to the presence of waves during the tests. Moreover, the amplitude is maximum at trailing edge, so it indicates the portion of water column the membrane goes through. Also, it is the easiest point where to read the amplitude, thus minimizing motion tracking relative uncertainty. Wave gauges measurements were not registered for the configuration with 12 dampers, so waves height are not available for this case. The motion amplitude at trailing edge is normalized by its value without waves. It shows that waves lead to $\pm 10 \%$ variations on the membrane amplitude. However, there is no linear trend according to waves frequency or significant height.
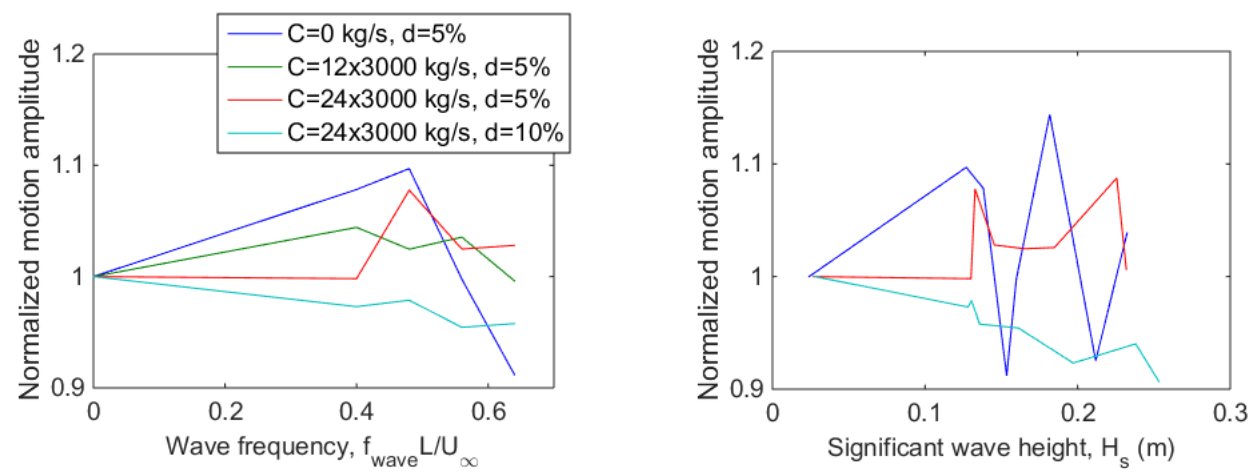

Figure 12: Mean motion amplitude variations due to incoming waves according to wave frequency (left) and mean wave height (right) for each tested configuration. Mean motion amplitude is normalized by its value for current only, with no waves. 
The same results for undulation frequency are presented in Fig. 13. It shows that waves-membrane interactions lead to up to $15 \%$ increase in undulation frequency in comparison with its value when it is submitted to current only. Here also there is no linear trend whatever the damping is, but the frequency spectrum analysis to be presented in the next section gives more information.
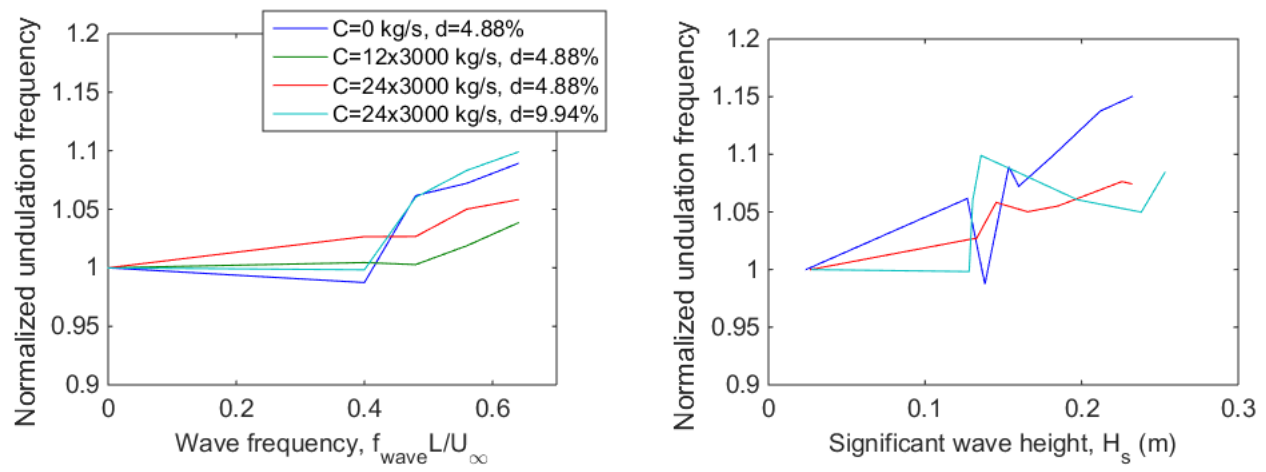

Figure 13: Main undulation frequency variations due to incoming waves according to wave frequency (left) and mean wave height (right) for each tested configuration. Main undulation frequency is normalized by its value for current only, with no waves.

\subsection{Frequency analysis}

The frequency analysis is carried out from Figs. 14 to 18. These figures present results of Fast Fourier Transform (FFT) of the trailing edge vertical position for different wave frequencies. Each graph is plotted for a different configuration, so it has a different fundamental frequency [11]. The peak associated to wave frequency is clearly visible on every curve. An example of trailing edge motion FFT is plotted in Fig. 14. Each spectrum has two peaks : one at the membrane main undulation frequency and the other at the wave frequency. The first and second harmonics are also sometimes visible.

Frequency spectrums of the trailing edge motion for the undamped configuration with various regular wave frequencies $f_{\text {wave }}^{*}$ are represented in Fig. 15 and in Fig. 16, which is a zoom of the same graph around $f^{*}$. In this configuration, tested wave frequencies are close to the membrane undulation frequency: $f^{*} \approx 0.45$. This enables to notice that the amplitude of the peak at wave frequency gets higher if it is close to the membrane undulation frequency. This result is highlighted by the dotted line linking wave frequency peaks. 


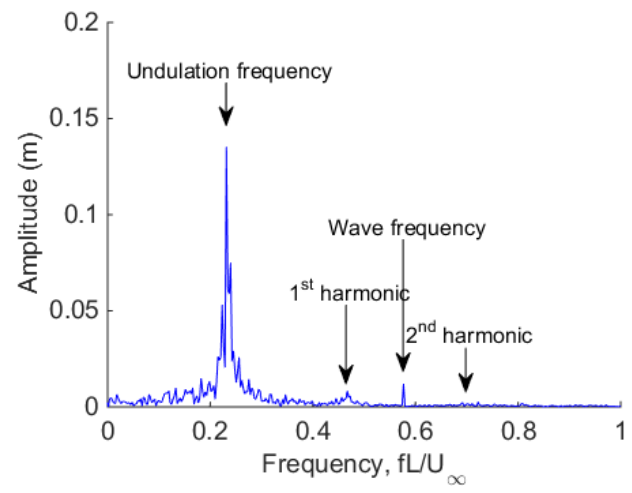

Figure 14: Example of Fast Fourier Transform of the undulating membrane tidal energy converter trailing edge vertical position submitted to regular waves of frequency $f_{\text {wave }} L / U_{\infty}=0.58$ and significant height $H_{s}=0.16 \mathrm{~m} . U_{\infty}=1 \mathrm{~m} / \mathrm{s}, d=5 \%$, $C=12 \times 3000 \mathrm{~kg} / \mathrm{s}$.
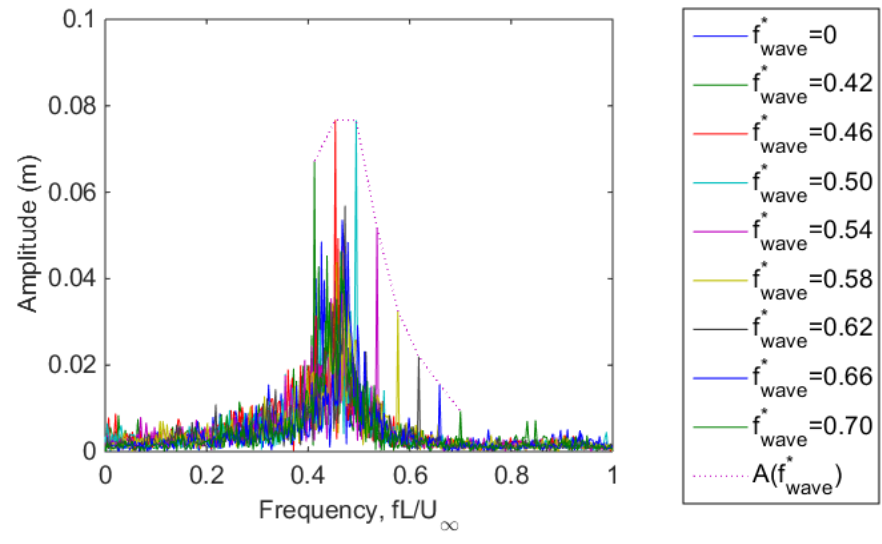

Figure 15: Fast Fourier Transform of the trailing edge vertical position for different regular wave frequencies. $U_{\infty}=1 \mathrm{~m} / \mathrm{s}, d=5 \%, C=0 \mathrm{~kg} / \mathrm{s}$.

However it is important to highlight that the "no wave" motion spectrum is widely spread because of the wave generator disturbances, and that the corresponding undulation frequency is not well-defined. Indeed, a zoom of the above graph is presented in Fig. 16 for selected trials. The blue and green lines represent the results with and without wave generator. 
A coupling occurs when the wave frequency is close enough to the membrane's one (from a distance of $\approx \pm 10 \%$ ). The main undulation frequency then synchronizes on the wave frequency. In Fig. 16, the $f_{\text {wave }}^{*}=0.49$ spectrum has only one peak at the wave frequency, whereas the $f_{\text {wave }}^{*}=0.58$ spectrum has two peaks : one at wave frequency and the other at the membrane's undulation one. This explains why, in Fig. 13, the undulation frequency of the undamped membrane starts to decrease (when $f_{\text {wave }}<f_{\text {undulation }}$ ), then increases when $f_{\text {undulation }}<f_{\text {wave }}$.

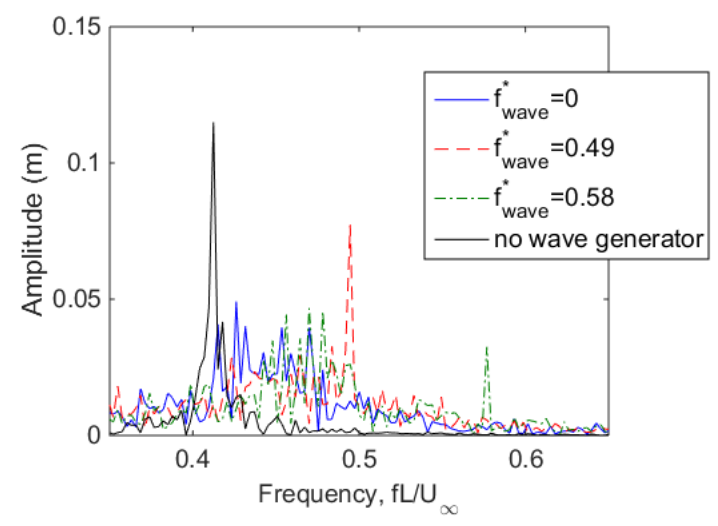

Figure 16: Fast Fourier Transform of the trailing edge vertical position with and without wave generator and with two regular wave frequencies: $f_{\text {wave }}^{*}=0.49$ and $f_{\text {wave }}^{*}=0.58$. $U_{\infty}=1 \mathrm{~m} / \mathrm{s}, d=5 \%, C=0 \mathrm{~kg} / \mathrm{s}$ (zoom of Fig. 15 for a few configurations).

In the case of an undulating membrane equipped with 12 dampers, frequency spectrums of the trailing edge vertical position are plotted in Fig 17. The amplitude of the wave frequency peak is much smaller than the main frequency one. However, it can still have some influence. The spectrum of the configuration for which the wave frequency is the closest to the system's first harmonic $\left(f_{1}^{*}=0.48\right)$ presents a higher wave peak than the spectrums of the other configurations. There is indeed a coupling between this wave frequency and the first harmonic. This interaction generates a shift in the fundamental frequency, that takes the value of half the wave frequency. We can conclude that there is a synchronization phenomenon, such as for the synchronization noticed in Fig. 15 between the wave frequency and the fundamental. 

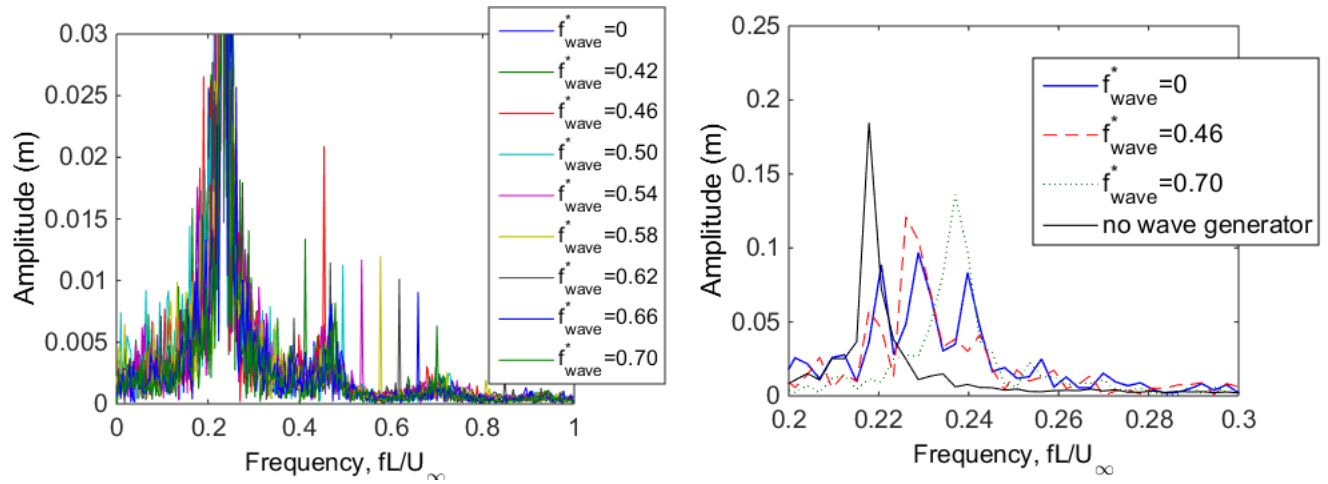

Figure 17: Fast Fourier Transform of the trailing edge vertical position for different regular wave frequencies. $U_{\infty}=1 \mathrm{~m} / \mathrm{s}, d=5 \%, C=12 \times 3000 \mathrm{~kg} / \mathrm{s}$. Left : zoom on the wave peaks. Right : zoom on the fundamental peaks for a few configurations.

This phenomenon is noticeable in the right graph of Fig. 17. The frequency content of the membrane's trailing edge motion is visible for trials with and without wave generator, and for two different regular wave frequencies. Without wave generator, the undulation frequency is $f L / U_{\infty}=0.218$. With wave generator but without waves, velocity fluctuations cause the spectrum to be wider and to spread between $f^{*}=0.21$ and $f^{*}=0.25$. For $f_{\text {wave }}^{*}=0.46$, the main frequency is clearly defined and a peak appears at $f^{*}=0.226 \approx f_{\text {wave }}^{*} / 2$. For $f_{\text {wave }}^{*}=0.70$, the peak is at $f^{*}=0.237 \approx f_{\text {wave }}^{*} / 3$. This suggests that the coupling between the wave frequency and the system's harmonics might shift the membrane's motion fundamental frequency.

Frequency spectrums of the membrane equipped with 24 dampers are presented in Fig. 18 for various regular wave frequencies. This configuration does not seem to present synchronization phenomenon. It is then possible that a high damping prevents it. In general, the membrane is less sensitive to wave effects when it's damped, as wave peaks ampitudes are higher in the undamped configuration spectrums. Indeed, the undulation frequency results from an equilibrium of the membrane's stiffness, the system's damping and the fluid's inertia on one side, and the excitation from the flow on the other side. A damped membrane requires then more energy to change its frequency. This explain why the synchronisation is more difficult to reach with additional damping from the converters. 


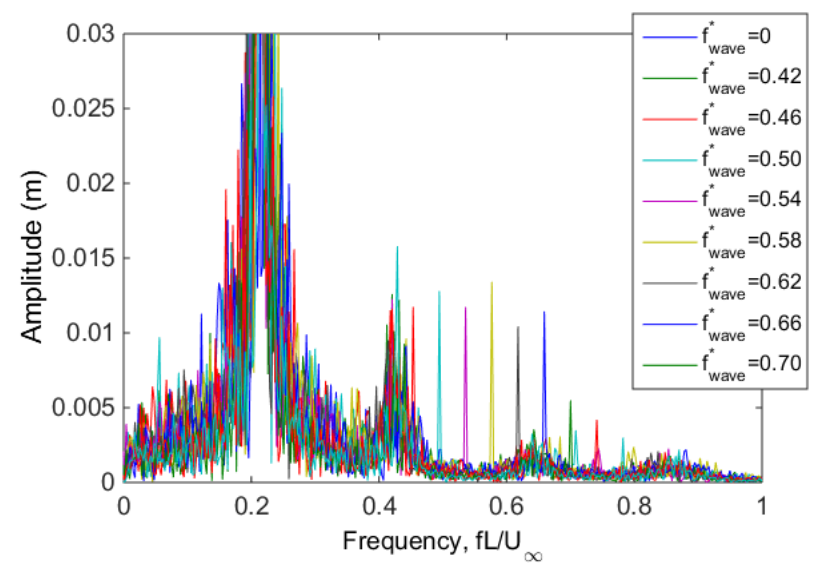

Figure 18: Fast Fourier Transform of the trailing edge vertical position for different regular wave frequencies. $U_{\infty}=1 \mathrm{~m} / \mathrm{s}, d=5 \%, C=24 \times 3000 \mathrm{~kg} / \mathrm{s}$.

The other tested configurations frequency spectrum are presented in Appendix A. In every figure, peaks with a frequency higher than $f_{\text {wave }}^{*}=0.7$ have an amplitude that strongly decrease according to their frequency. This can be due to the system's response time being too long compared to the wave period. These waves can still influence the undulation main frequency and its harmonics. In the case $C=24 \times 3000 \mathrm{~kg} / \mathrm{s}, U_{\infty}=0.85 \mathrm{~m} / \mathrm{s}, d=5$ $\%$, the first harmonic has a higher amplitude when the membrane is submitted to regular waves of frequency $f_{\text {wave }}^{*}=0.78$, which is close to the value of its third natural harmonic $\left(f_{3}^{*}=0.73\right)$. Moreover, this creates a shift of the fundamental and its harmonics into fractions of the wave frequency. The fundamental is then at $f^{*} \approx 1 / 4 \times f_{\text {wave }}^{*}=0.78 / 4=0.195$ instead of $f^{*}=0.18$.

Finally, on most of the spectrums plotted here, the wave peak at $f_{\text {wave }}^{*} \approx$ 0.58 is higher than its neighbours. This is valid for all tested configurations with damped membranes. This curiosity is not explained here and has little impact in comparison to the interactions between regular waves and the natural harmonics of the system. 


\subsection{Forces variations}

After analysing the membrane motion response to surface waves, their effects on the hydrodynamic forces is studied. The evolution in time of the lift and drag coefficients (Eq. $7 \& 8$, where $\rho_{f}$ is the fluid density, $L$ the membrane's length, $b$ its width and $U_{\infty}$ the flow speed) is presented in Figs. $19 \& 20$ for a configuration without wave and an another with regular waves of frequency $f_{\text {wave }}^{*}=0.58$ and significant height $H_{s}=0.18 \mathrm{~m}$. The vertical component of orbital speed $W_{\text {orb }}^{*}$ in the surface at $x=0 \mathrm{~mm}$, is also plotted. It is calculated as being the derivative of the surface elevation. The impact of waves loading is significant, generating variations in the force signals from a cycle to another. The synchronization of lift variations with the vertical orbital speed is visible in Fig. 19. On the other hand, there is a shift in Fig. 20 between drag variations and $W_{o r b}^{*}$. Such a shift is expected because drag is sensible to horizontal speed variations $U_{\text {orb }}^{*}$, which should have a $\pi / 2$ phase difference with the vertical component of wave orbital speed.

$$
\begin{aligned}
C_{l} & =\frac{F_{z}}{0.5 \rho_{f} L b U_{\infty}^{2}} \\
C_{d} & =\frac{F_{x}}{0.5 \rho_{f} L b U_{\infty}^{2}}
\end{aligned}
$$
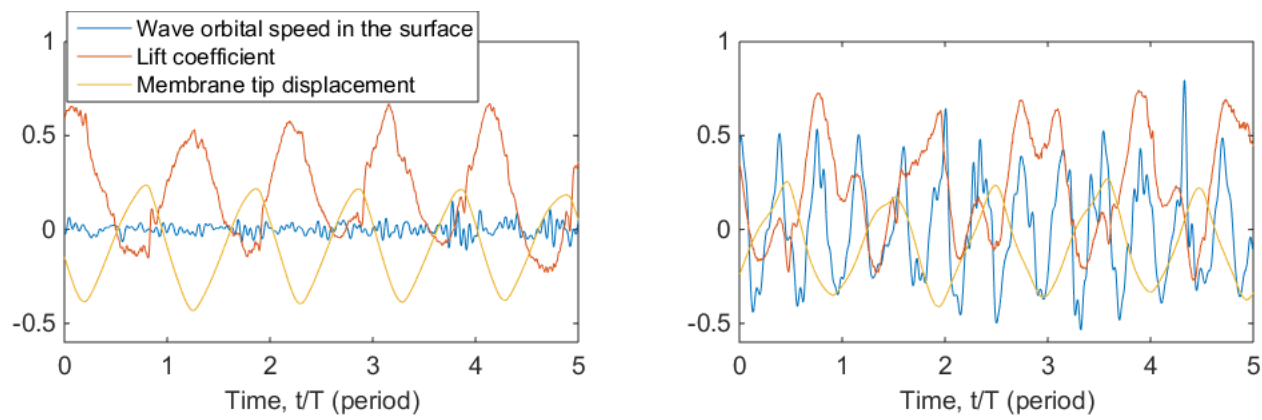

Figure 19: Lift coefficient evolution of the membrane: $C_{l}=F_{z} /\left(0.5 \rho L b U_{\infty}^{2}\right)$; vertical tip displacement (yellow): $y_{L}^{*}=y_{L} / L$; and vertical wave orbital speed in the surface: $W_{\text {orb }}^{*}=W_{\text {orb }} / U_{\infty}$ (blue) without (left) and with waves (right, $f_{\text {wave }}^{*}=0.58$ and $H_{s}=0.18$ m) during 5 undulation periods. $C=24 \times 3000 \mathrm{~kg} / \mathrm{s}, d=5 \%, U_{\infty}=1 \mathrm{~m} / \mathrm{s}$ 

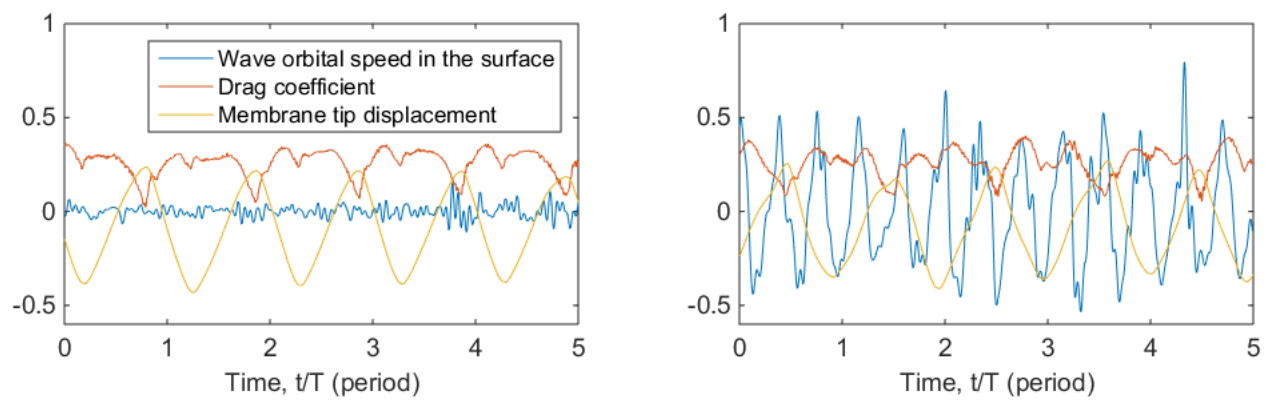

Figure 20: Drag coefficient evolution of the membrane: $C_{d}=F_{x} /\left(0.5 \rho L b U_{\infty}^{2}\right)$; vertical tip displacement (yellow): $y_{L}^{*}=y_{L} / L$; and vertical wave orbital speed in the surface: $W_{\text {orb }}^{*}=W_{\text {orb }} / U_{\infty}$ (blue) without (left) and with waves (right, $f_{\text {wave }}^{*}=0.58$ and $H_{s}=0.18$ m) during 5 undulation periods. $C=24 \times 3000 \mathrm{~kg} / \mathrm{s}, d=5 \%, U_{\infty}=1 \mathrm{~m} / \mathrm{s}$

The values of maximum lift and drag forces are modified according to the wave frequency and significant height. However, as noted for the undulating motion (Figs. $12 \&$ 13), there is no clear tendency between forces and waves characteristics. The tested wave range leads to up to $17 \%$ increase in maximum lift and up to $31 \%$ increase in maximum drag for the undamped configuration, and up to $11 \%$ lift and $25 \%$ drag increase for the damped configurations. Wave loading generates disturbances in the forces on the structure that are generally not synchronized with the undulation period of the membrane. Therefore, it adds variations from a cycle to another, increasing maximum forces but not their mean value.
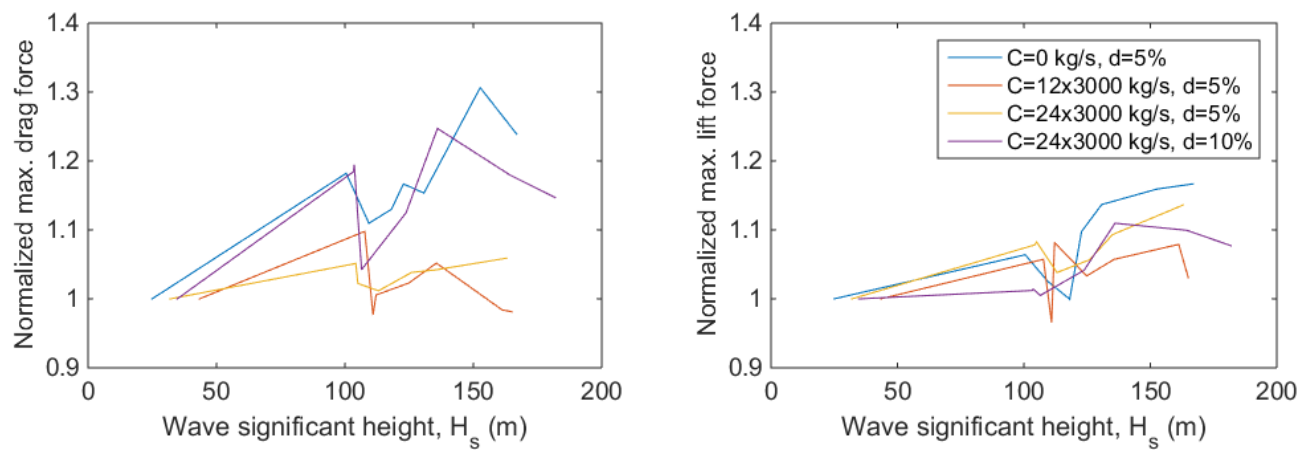

Figure 21: Mean motion drag (left) and lift (right) coefficient variations due to incoming waves according to mean wave height for each tested configuration. Mean force coefficient is normalized by its value for current only, with no waves. 
Fast Fourier Transform of force signals are presented in Figs. $22 \& 23$ for the configuration $C=24 \times 3000 \mathrm{~kg} / \mathrm{s}, d=5 \%$ and $U_{\infty}=1 \mathrm{~m} / \mathrm{s}$. Peaks at wave frequencies can here also be noticed. These peaks are greater in absolute value on the lift spectrum but, relative to the fundamental amplitude, they are higher in the drag spectrum.

In the lift spectrum, the same conclusions as the motion spectral analysis can be made:

- damping due to power conversion reduces the effect of waves,

- the influence of waves with a non-dimensional frequency $f_{\text {wave }}^{*} \geq 0.7$ is significantly lower,

- synchronization occurs when the wave frequency is close to the system's fundamental or one of its harmonics,

- there is a local maximum of the regular waves' peak amplitude at $f_{\text {wave }}^{*}$ $=0.58$.

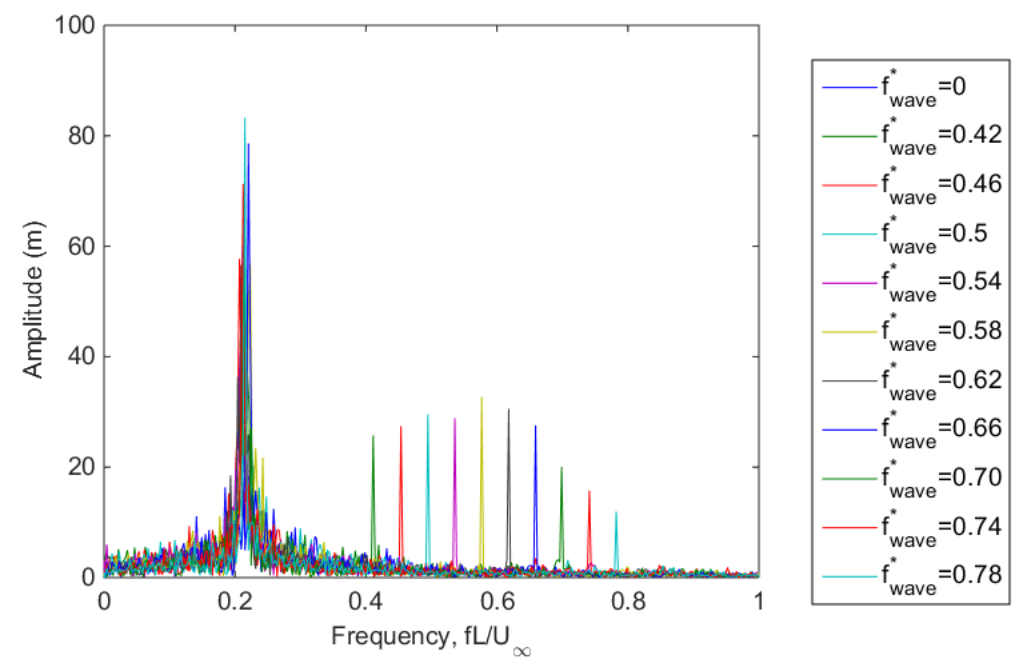

Figure 22: Fast Fourier Transform of the lift force for different regular wave frequencies. $U_{\infty}=1 \mathrm{~m} / \mathrm{s}, d=5 \%, C=24 \times 3000 \mathrm{~kg} / \mathrm{s}$. 

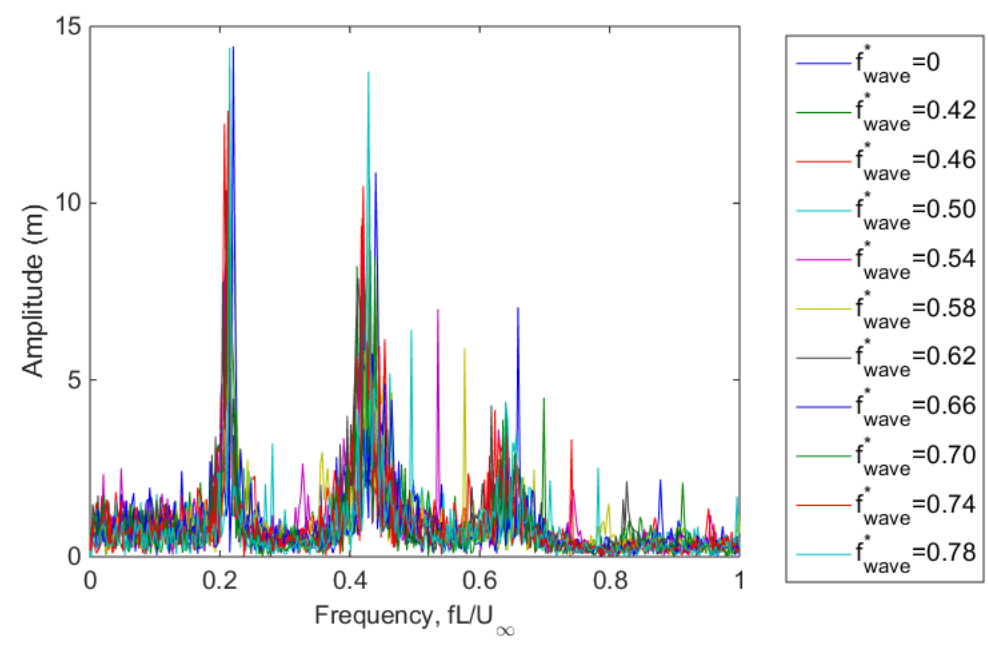

Figure 23: Fast Fourier Transform of the drag force for different regular wave frequencies. $U_{\infty}=1 \mathrm{~m} / \mathrm{s}, d=5 \%, C=24 \times 3000 \mathrm{~kg} / \mathrm{s}$.

About the drag spectrum, the above first two affirmations are true but not the two others. It appears that the drag response to surface waves is more complex and would require further analysis. Indeed, it can be noticed that the waves generates peaks at specific frequencies, without any constant ratio between the wave frequencies and these specific frequencies. For example, for regular waves with a frequency of $f_{\text {wave }}^{*}=0.54$, a peak can be observed at $f^{*}$ $=0.33$ and another at $f^{*}=0.74$; whereas regular waves with a frequency of $f_{\text {wave }}^{*}=0.50$ generates peaks at $f^{*}=0.28$ and $f^{*}=0.71$. This phenomenon could come from complex interactions between the surface waves and the membrane but could also be linked to the support frame's stiffness or to the rest of the experimental set-up.

\subsection{Power conversion}

The power converted by the undulating membrane tidal energy converter small-scale model is calculated by interpolating the hydraulic dampers' position from the motion-tracking measurement. Then, the activation speed of the dampers is calculated by a simple-order finite difference scheme and the force is estimated as being purely proportional to the damper's speed. The total converted power is then the average over 10 periods of the product between the damping force and the damper's activation speed summed for every dampers. 
The variation of the converted power due to the presence of surface wave is presented in Fig 24 according to wave frequency and significant height. It appears that the converted power tends to be greater in the presence of waves. The hydraulic dampers used to model linear converter, combined with the undulating membrane are then able to absorb part of the additionnal energy that the waves induce to the system. However, no clear trends of this increase in power have been found in relation to wave characteristics or wave power.
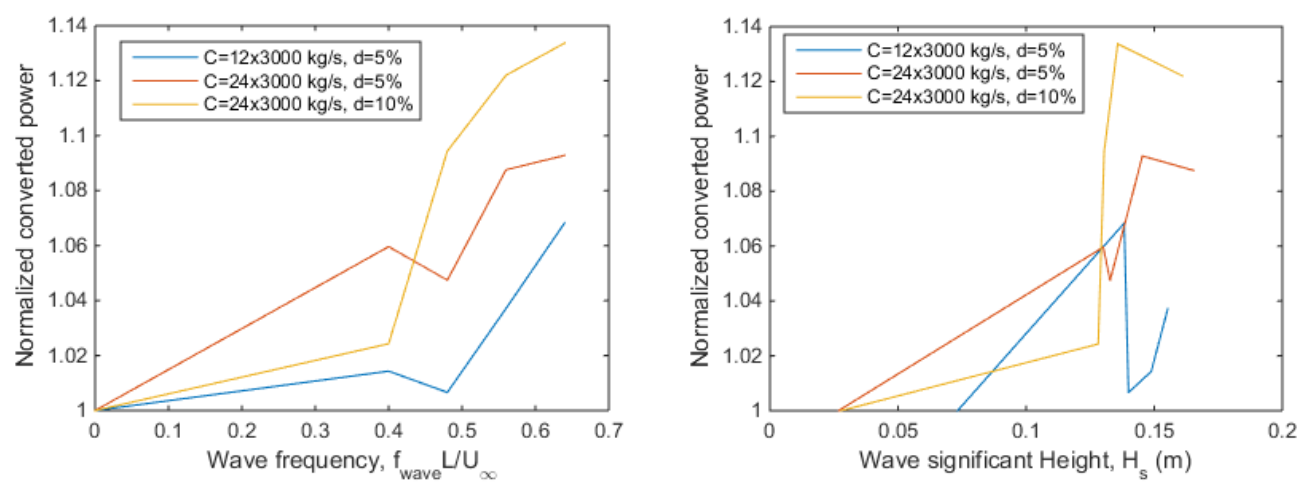

Figure 24: Mean converted power variations due to incoming waves according to wave frequency (left) and mean wave height (right) for each tested configuration. Mean converted power is normalized by its value for current only, with no waves.

No relation has been found between the membrane's additional power conversion and the waves mean power. However, the surface wavelength is great in comparison to the membrane's length. It would be interesting to experiment the membrane's response to waves with wavelength close to or smaller than its length. The IFREMER flume tank is not suited for this experiment, as it cannot generate waves of these wavelengths with sufficient amplitude.

\subsection{Irregular waves loading}

The experiments with regular waves give interesting results, but it is more realistic to consider irregular waves. Therefore, waves have been modeled with a JONSWAP spectrum $\left(H_{s}=0.107 \mathrm{~m}, T_{p}=1.65 \mathrm{~s}\right)$ [13]. The evolution of drag and lift coefficient, along with the vertical component of the wave orbital speed is plotted in Fig. 25. Unlike for regular waves loading, the membrane does not seem to react to each wave at irregular frequency, 
except maybe for the highest ones. The wave frequency variations appear to cancel the synchronisation between the waves and the membrane's forces and motion. The system having significant inertia, each wave can change a little the frequency of the system. If the waves are regular in frequency, the system can reach the synchronisation after a certain time. However, in the case of irregular waves, the wave frequency changes from one wave to another in a "random" way. Therefore, the system cannot synchronize with it, as it has not the time to reach a new equilibrium.

Fig. 26 shows the trailing edge displacement signal spectrum and Figs. $27 \& 28$ present the drag and lift signals spectrum for a test with irregular waves. For a better understanding, the frequency spectrum of the free surface elevation measured in $x=0$ has been superimposed on the graphs. For a better visibility, this spectrum is expressed in meters in the displacement spectrum graphic and in centimeters for the lift and drag figures. The lift signal spectrum is the only one where the influence of the irregular waves is visible in the tested wave frequency range. Superimposition with a lift spectrum of the same configuration without any wave is not presented here but would present a significant difference in this frequency range. However, this is not the case for the drag force spectrum nor the trailing edge's displacement spectrum.
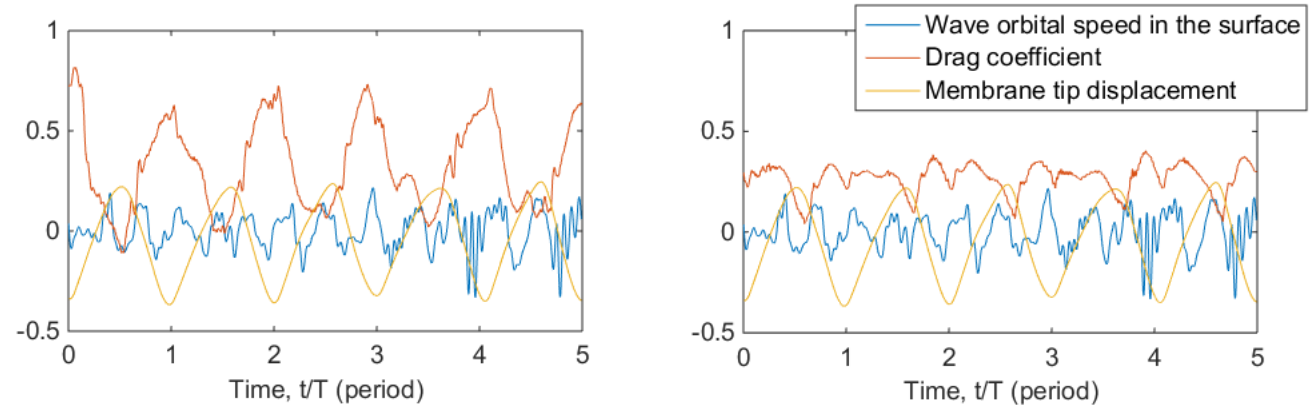

Figure 25: Lift (left) and drag (right) coefficient evolution of the membrane (red): $C_{l}=$ $F_{z} /\left(0.5 \rho L b U_{\infty}^{2}\right), C_{d}=F_{x} /\left(0.5 \rho L b U_{\infty}^{2}\right)$; vertical tip displacement (yellow): $y_{L}^{*}=y_{L} / L$; and vertical wave orbital speed in the surface: $W_{\text {orb }}^{*}=W_{\text {orb }} / U_{\infty}$ (blue) during 5 undulation periods. $C=24 \times 3000 \mathrm{~kg} / \mathrm{s}, d=5 \%, U_{\infty}=1 \mathrm{~m} / \mathrm{s}$ with irregular waves $\left(H_{s}=107 \mathrm{~mm}\right.$, $\left.T_{p}=1.65 \mathrm{~s}\right)$. 


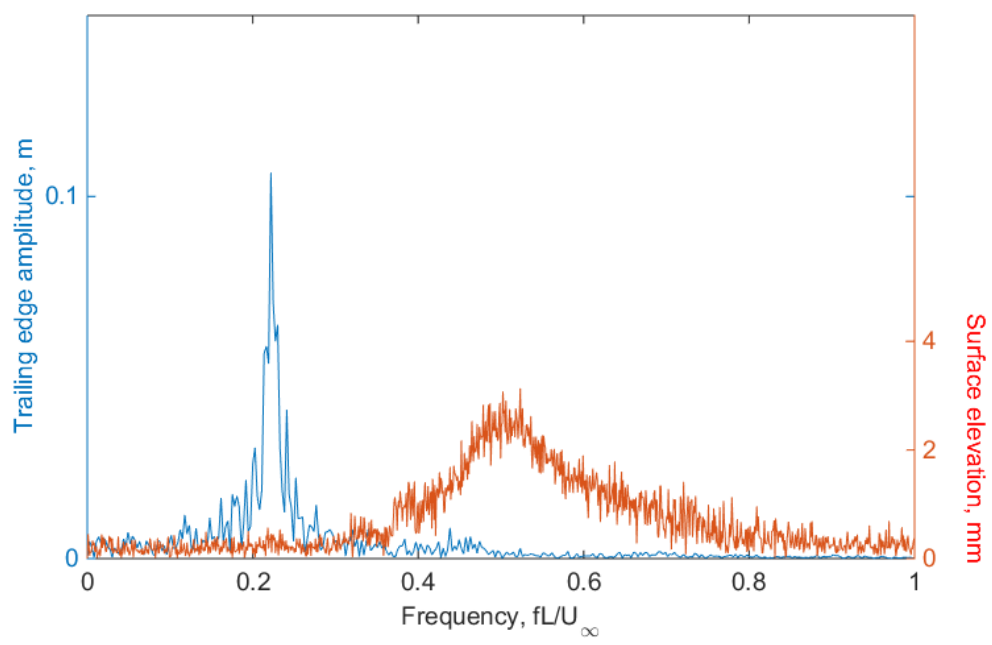

Figure 26: Fast Fourier Transform of the trailing edge vertical position and the surface elevation for irregular waves $\left(H_{s}=0.107 \mathrm{~m}, T_{p}=1.65 \mathrm{~s}\right) . U_{\infty}=1 \mathrm{~m} / \mathrm{s}, d=5 \%$, $C=12 \times 3000 \mathrm{~kg} / \mathrm{s}$.

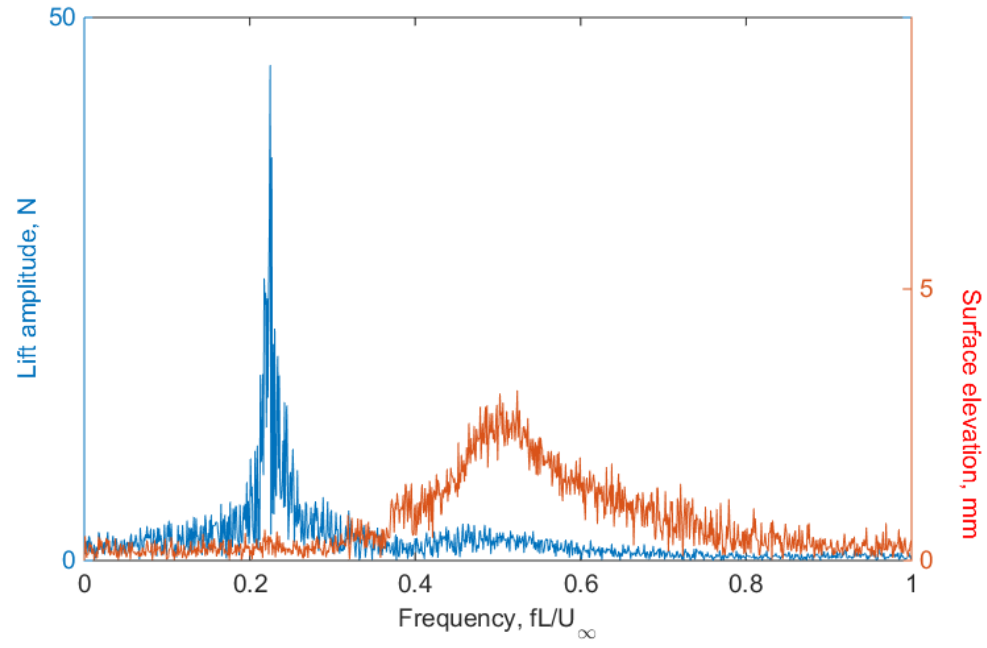

Figure 27: Fast Fourier Transform of the lift force and the surface elevation for irregular waves $\left(H_{s}=0.107 \mathrm{~m}, T_{p}=1.65 \mathrm{~s}\right) . U_{\infty}=1 \mathrm{~m} / \mathrm{s}, d=5 \%, C=24 \times 3000 \mathrm{~kg} / \mathrm{s}$. 


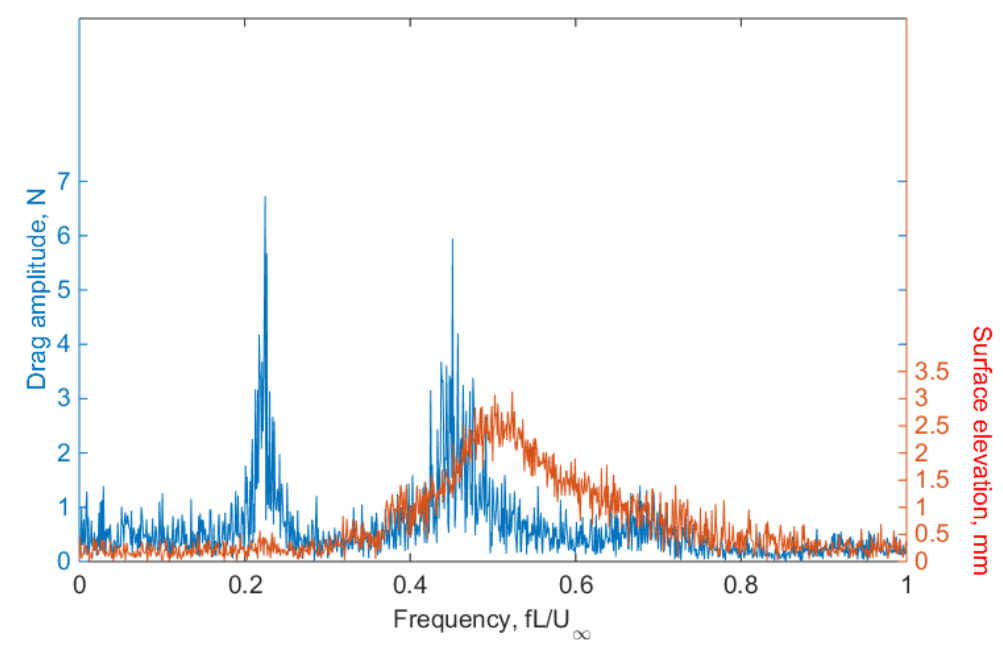

Figure 28: Fast Fourier Transform of the drag force and the surface elevation for irregular waves $\left(H_{s}=107 \mathrm{~mm}, T_{p}=1.65 \mathrm{~s}\right) . U_{\infty}=1 \mathrm{~m} / \mathrm{s}, d=5 \%, C=12 \times 3000 \mathrm{~kg} / \mathrm{s}$.

\section{Conclusion and perspectives}

Waves loading on the undulating membrane tidal energy converter has been studied for the first time from measurements obtained in a wave and current tank. Respecting the scale factor and Froude similitude, tested surface waves are representative at real scale $(L=15 \mathrm{~m})$ of waves up to $H_{s}=$ $5.1 \mathrm{~m}$ and $f_{\text {wave }}=0.19 \mathrm{~Hz}$. Significant influence of waves on the behaviour of the membrane has been noticed and analysed.

The presence of the wave generator in the front of the test section modifies the current profile and causes speed fluctuations in its wake, impacting the behaviour of the undulating membrane tidal converter. This generates an acceleration of the flow speed of around $5 \%$ at the prototype's position, resulting in an increase of the membrane's undulation frequency. The velocity fluctuations also generate little perturbations in the membrane's motion, leading to wider frequency spectrums and higher amplitudes of vertical motion and lift force. However, the undulation mode of the membrane's dynamic behavior is not modified. 
Only the response to waves in the same directions as the current as been experimented here. Further experiments should be done with the wave generator placed downstream, generating couter-current surface waves. It would be interesting to compare wave-induced additional loadings according to their direction. Transverse waves could also be studied, but this would recquire to do the experiment in another facility.

No direct link could be identified between wave frequency or significant height and the mean and maximum values of measured forces or membrane dynamic. Waves do not change significantly the average values of forces on the structure but tend to increase the fluctuations of hydrodynamic loads.

The frequency spectrum analysis of measured signals have enabled to notice several interesting phenomenons:

1. the damping (here modelling PTO) reduces the influence of wave loading on the membrane,

2. for all tested configurations, there is a strong decrease of the influence of wave loading for wave frequencies $f_{\text {wave }}^{*} \geq 0.7$,

3. there is a synchronization phenomenon when the wave frequency is close to the system's fundamental or one of its main harmonics,

4. no synchronisation has been noticed for irregular waves conditions.

The undulating membrane tidal energy converter's response to wave loads highly depends on the wave frequency. In this, it is different from classical horizontal axis tidal turbines. Another difference in the loads spectrum is the wave frequency being minor in front of the membrane undulation frequency.

Overall, waves in the tested range have little to no influence on the performance and mean power production of the undulating tidal energy converter. Concerning the design of the future real scale undulating membrane tidal energy converter and its support structure, an increase of $30 \%$ of the forces must be foreseen in case of wave condition in the tested range. An equivalent study with a higher turbulence intensity would also be very useful in order to prepare open sea trials. Further tests should also monitor the membrane's stress and strain because these parameters are also very important to design prototypes resistance and lifespan. 


\section{Nomenclature}

\begin{tabular}{|c|c|c|}
\hline Parameter & Unit & Description \\
\hline$A_{\text {wave }}$ & $\mathrm{m}$ & Wave amplitude, as resqueted to the wave generator \\
\hline$b$ & $\mathrm{~m}$ & Membrane width \\
\hline$C$ & $\mathrm{~kg} / \mathrm{s}$ & Linear converter's damping coefficient \\
\hline$d$ & $\%$ & Pre-stress cable withdraw length \\
\hline$e$ & $\mathrm{~m}$ & Membrane thickness \\
\hline$f$ & $\mathrm{~Hz}$ & Undulation frequency \\
\hline$F_{d}$ & $\mathrm{~N}$ & Drag force \\
\hline$F_{l}$ & $\mathrm{~N}$ & Lift force \\
\hline$F_{r}$ & . & Froude Number \\
\hline$f_{s}$ & $\mathrm{~Hz}$ & Sampling frequency \\
\hline$f_{\text {wave }}$ & $\mathrm{Hz}$ & Wave frequency \\
\hline$F_{x}, F_{y}, F_{z}$ & & Axial, transverse and vertical component of measured force \\
\hline$g$ & $\mathrm{~m} \cdot \mathrm{s}^{-2}$ & Gravitational acceleration \\
\hline$h$ & $\mathrm{~m}$ & Flume tank height \\
\hline$H_{s}$ & $\mathrm{~m}$ & Significant wave height \\
\hline$H_{\text {wave }}$ & $\mathrm{m}$ & Wave peak-to-crest height \\
\hline$I_{2 D}$ & $\%$ & Turbulent intensity \\
\hline$k$ & $\mathrm{~m}^{-1}$ & Wave number \\
\hline$L$ & $\mathrm{~m}$ & Membrane length \\
\hline$P$ & $\mathrm{~W}$ & Mean converted power \\
\hline$P_{\text {wave }}$ & W & Wave mean power by unit width \\
\hline$T_{p}$ & s & Peak wave period \\
\hline$u, v, w$ & $\mathrm{~m} / \mathrm{s}$ & Horizontal, transverse and vertical component of flow speed \\
\hline$U_{\infty}$ & $\mathrm{m} / \mathrm{s}$ & Mean upstream flow speed \\
\hline$U_{c}$ & $\mathrm{~m} / \mathrm{s}$ & Critical flow speed \\
\hline$u_{\text {orb }}, v_{\text {orb }}, w_{\text {orb }}$ & $\mathrm{m} / \mathrm{s}$ & Axial, transverse and vertical component of orbital speed \\
\hline$x, y, z$ & $\mathrm{~m}$ & Horizontal, transverse and vertical position \\
\hline$z_{\text {surface }}$ & $\mathrm{m}$ & Free surface elevation \\
\hline$\lambda$ & $\mathrm{m}$ & Wavelength \\
\hline$\sigma()$. & . & Standart deviation of parameter (.) \\
\hline$\overline{-}$ & . & Time-average of parameter (.) \\
\hline$(.)^{\prime}$ & . & Variation of parameter (.) to its time-average \\
\hline$(.)^{*}$ & . & Non-dimensional value of parameter (.) \\
\hline
\end{tabular}




\section{Acknowledgment}

This work was supported by the French Environment and Energy Management Agency (ADEME), the French Research Institute for Exploitation of the Sea (IFREMER) and Eel Energy SAS.

\section{References}

[1] O. Durán Medina, F. G. Schmitt, R. Calif, G. Germain, and B. Gaurier, "Turbulence analysis and multiscale correlations between synchronized flow velocity and marine turbine power production," Renewable Energy, vol. 112, pp. 314-327, 2017.

[2] M. Ikhennicheu, G. Germain, P. Druault, and B. Gaurier, "Experimental study of coherent flow structures past a wall-mounted square cylinder," Ocean Engineering, vol. 182, pp. 137-146, 2019.

[3] P. W. Galloway, L. E. Myers, and A. S. Bahaj, "Quantifying wave and yaw effects on a scale tidal stream turbine," Renewable Energy, vol. 63, p. 297-307, 2014.

[4] R. Martinez, G. S. Payne, and T. Bruce, "The effects of oblique waves and currents on the loadings and performance of tidal turbines," Ocean Engineering, vol. 164, p. 55-64, 2018.

[5] S. Ordonez-Sanchez, M. Allmark, K. Porter, R. Ellis, C. Lloyd, I. Santic, T. O'Doherty, and C. Johnstone, "Analysis of a horizontal-axis tidal turbine performance in the presence of regular and irregular waves using two control strategies," Energies, vol. 12, 2019.

[6] S. Draycott, G. Payne, J. Steynor, A. Nambiar, and V. Sellar, B. Venugopal, "An experimental investigation into non-linear wave loading on horizontal axis tidal turbines," Philosophical Transactions of the Royal Society A: Mathematical, Physical and Engineering Sciences, vol. 371, pp. 199-217, 2019.

[7] B. Gaurier, P. Davies, A. Deuff, and G. Germain, "Flume tank characterization of marine current turbine blade behaviour under current and wave loading," Journal of Fluids and Structures, vol. 59, pp. 1-12, 2013. 
[8] P. Davies, G. Germain, B. Gaurier, A. Boisseau, and D. Perreux, "Evaluation of the durability of composite tidal turbine blades," Philosophical Transactions of the Royal Society A: Mathematical, Physical and Engineering Sciences, vol. 371, 2013.

[9] H. R. Mullings, T. J. Stallard, and G. Payne, "Operational loads on a tidal turbine due to environmental conditions," in Proceedings of the 27th International Ocean and Polar Engineering Conference, I. S. of Offshore and P. E. (ISOPE), Eds., 2017.

[10] S. Tully and I. M. Viola, "Reducing the wave induced loading of tidal turbine blades through the use of a flexible blade," in Proceedings of the 16th International Symposium on Transport Phenomena and Dynamics of Rotating Machinery, I. 2016), Ed., 2016.

[11] M. Träsch, A. Déporte, S. Delacroix, G. Germain, B. Gaurier, and J.B. Drevet, "Power estimates of an undulating membrane tidal energy converter," Ocean Engineering, vol. 148, pp. 115-124, 2018.

[12] M. Träsch, "Caractérisation expérimentale et numérique du comportement hydrodynamique d'une hydrolienne à membrane ondulante," Ph.D. dissertation, Université de Lille, 2019.

[13] D. E. Hasselmann, M. Dunckel, and J. A. Ewing, "Directional wave spectra observed during jonswap 1973," Journal of Physical Oceanography, vol. 10, pp. 1264-1280, 1980.

[14] A. Boutier, D. Arnal, L. David, M. Elena, J. Haertig, and B. Lecordier, Laser Velocimetry in Fluid Mechanics. ISTE, 2013.

[15] B. Gaurier, G. Germain, J.-V. Facq, and T. Bacchetti, "Wave and current flume tank of ifremer at boulogne-sur-mer," Tech. Rep., 2018.

[16] I. Jonsson, "Wave-current interactions," Ocean Engineering Science, vol. 9A, pp. 65-120, 1990. 


\section{Appendix A. Frequency spectrum of trailing edge position for various configurations}

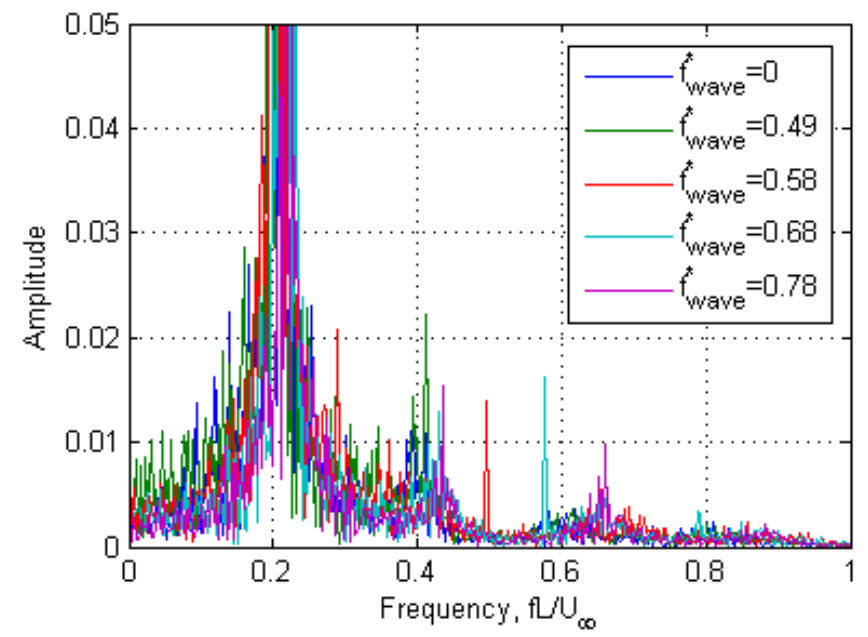

Figure A.29: Fast Fourier Transform of the drag force for different regular wave frequencies. $U_{\infty}=1 \mathrm{~m} / \mathrm{s}, d=10 \%, C=24 \times 3000 \mathrm{~kg} / \mathrm{s}$. 


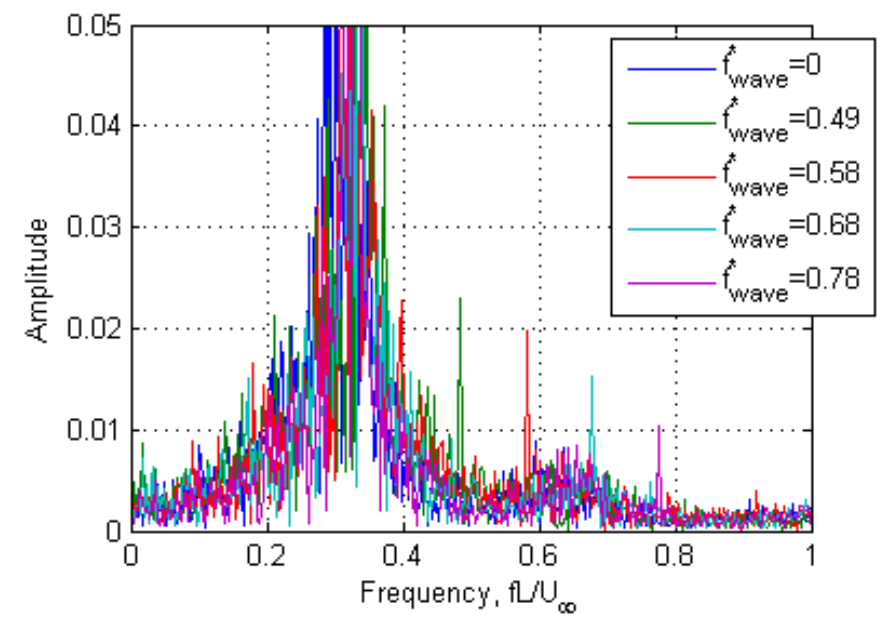

Figure A.30: Fast Fourier Transform of the drag force for different regular wave frequencies. $U_{\infty}=0.85 \mathrm{~m} / \mathrm{s}, d=5 \%, C=0 \mathrm{~kg} / \mathrm{s}$.

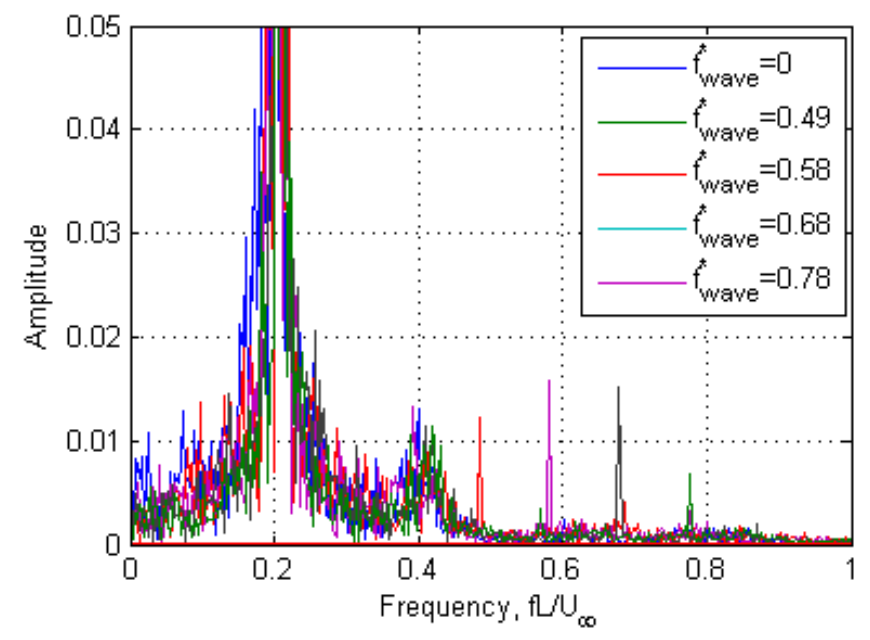

Figure A.31: Fast Fourier Transform of the drag force for different regular wave frequencies. $U_{\infty}=0.85 \mathrm{~m} / \mathrm{s}, d=5 \%, C=12 \times 3000 \mathrm{~kg} / \mathrm{s}$. 


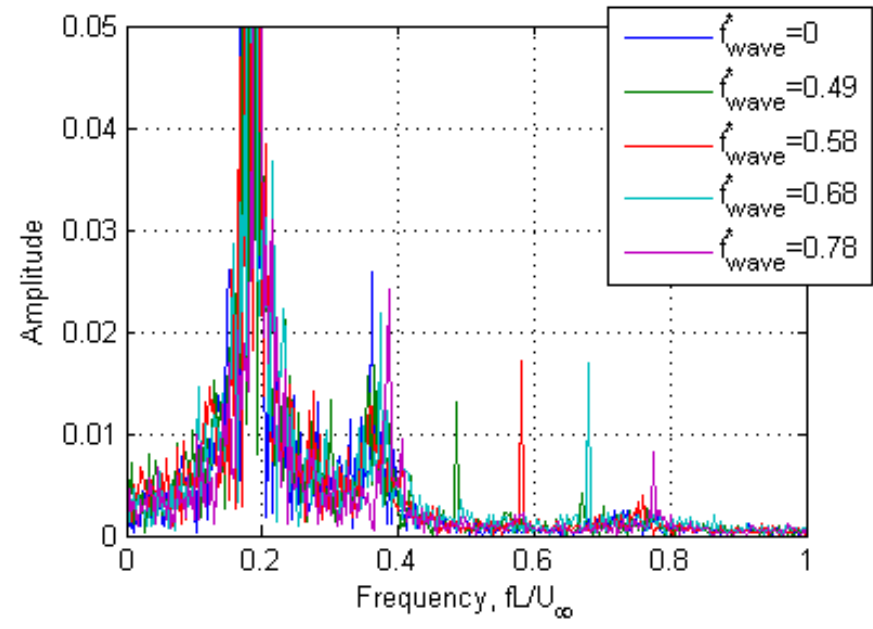

Figure A.32: Fast Fourier Transform of the drag force for different regular wave frequencies. $U_{\infty}=0.85 \mathrm{~m} / \mathrm{s}, d=5 \%, C=24 \times 3000 \mathrm{~kg} / \mathrm{s}$.

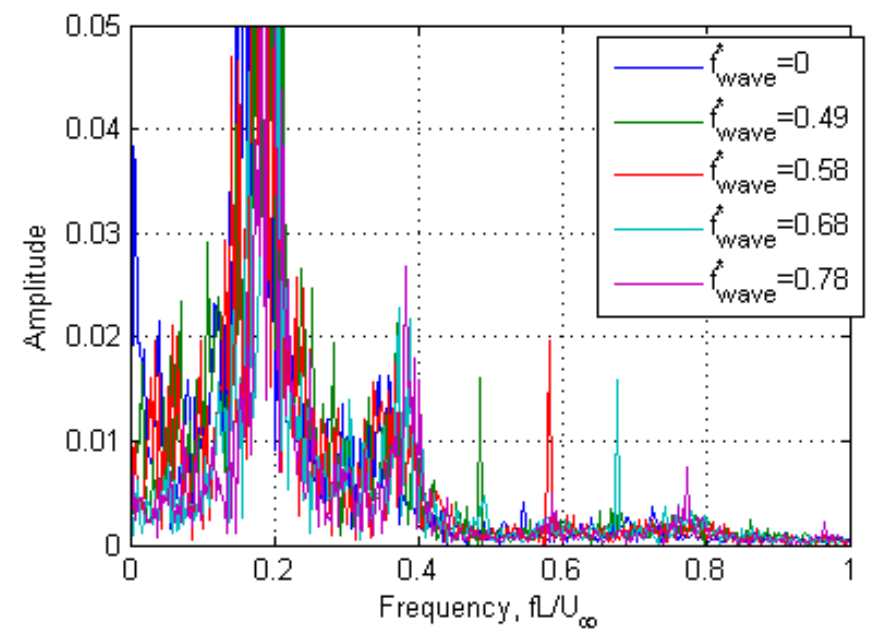

Figure A.33: Fast Fourier Transform of the drag force for different regular wave frequencies. $U_{\infty}=0.85 \mathrm{~m} / \mathrm{s}, d=10 \%, C=24 \times 3000 \mathrm{~kg} / \mathrm{s}$. 